\title{
La ciudad, los lugares y los actores
}

\author{
Sergio Tamayo
}

MIGUEL ÁNGEL AGUILAR, AMPARO SEVILLA

Y ABILIO VERGARA (coords.), 2001

\section{La ciudad desde sus lugares. Trece ventanas etnográficas para una metrópoli}

E 1 libro consta de dos partes, una dedicada a los lugares donde se recrea el cuerpo de distintas maneras, en el baile, en los antros o en las peluquerías; la otra se orienta hacia aquellos lugares de tipo comercial, recreativo, residencial y religioso que existen en la ciudad de México. La mirada de los autores es multidisciplinaria y parte de un profundo trabajo etnográfico: se apoya en la antropología, la psicología social, el patrimonio cultu- ral, la cultura urbana, las identidades sociales y barriales, y la etnomusicología. Es resultado del Seminario Permanente de Cultura y Ciudad, instituido desde 1996 por los coordinadores.

A continuación describo brevemente la estructura del libro. La introducción de Abilio Vergara está dedicada al tema del lugar antropológico. Es un trabajo analítico que aloja suavemente al lector en el complejo discur-

SERGIO TAMAYO: UAM-Azcapotzalco.

Desacatos, núm. 15-16, otoño-invierno 2004, pp. 244-247.

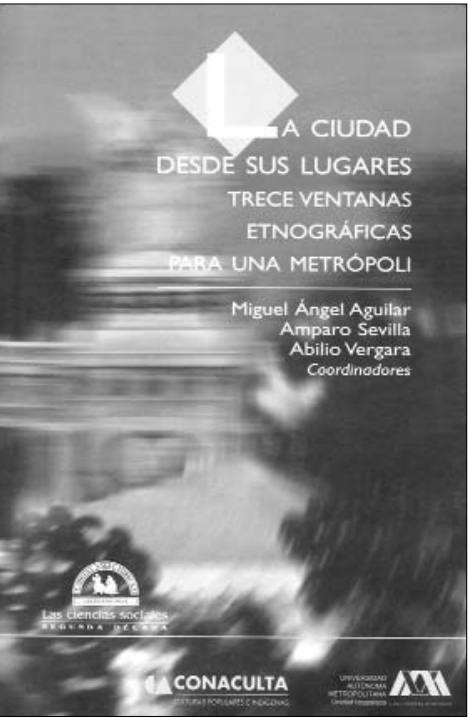

so de las identidades urbanas, del espacio y de la interdisciplina. Después se abre la primera parte. Hay dos artículos de Amparo Sevilla sobre los salones de baile, el de Los Ángeles y el Aditec. Enseguida Edgar Morín, con los skándalos juveniles, nos introduce a otro antro, el Alicia. Mauricio List muestra el caso de un antro gay, la Lili. Continúa la descripción, por parte de Ernesto Licona, de una peluquería 
de Tacubaya y de la construcción de identidades masculinas. Al final de la primera parte Judith Katia Perdigón presenta el pasillo 8 del mercado de Sonora, con su peculiar atmósfera y olores.

Este primer acercamiento permite acceder a un escenario vigoroso de la ciudad nocturna: El salón Los Ángeles en la Guerrero, el Aditec cerca del Chopo, el Alicia en la avenida Cuauhtémoc, cerca de Álvaro Obregón, la Lilí en la colonia Puebla por la Magdalena Mixhuca, una peluquería en Tacubaya y el mercado de Sonora, al oriente de Fray Servando Teresa de Mier.

La coherencia del libro está en la pertinencia del estilo etnográfico, en la discusión metodológica del examen antropológico del lugar urbano y en la demostración de que el estudio del lugar nos remite a entender ciertos elementos constitutivos de las identidades urbanas. La estructura analítica se define por las siguientes preguntas: ¿Cuál es la relación entre el adentro y el afuera de un lugar? ¿Cuál es el vínculo entre el lugar y la ciudad? ¿A través de qué redes sociales y espaciales, un lugar se encuentra con la ciudad? ¿De qué actores hablamos cuando explicamos un salón de baile, un espacio gay o una peluquería masculinizante? ¿Cómo se expresan las identidades en estos lugares, a pesar de sus diferencias en cuanto a funciones, objetivos, significados y apropiaciones sociales? ¿Cómo se describe físicamente el espacio desde la antropología, la sociología o la psicología?

La segunda parte está dedicada a los espacios comerciales, residenciales y religiosos. Los temas se ubican en el análisis de las plazas públicas, los centros comerciales, las vecindades y la iglesia. Nos encontramos con lugares como Tlalpan, Insurgentes Sur y San Fernando, el centro de Tlalpan y Plaza Cuicuilco. El itinerario nos lleva después a Plaza Satélite, junto a las Torres de Barragán y Goeritz; de regreso estamos en Plaza Universidad, en la Benito Juárez. Se describe el ambiente que genera el juego de billar en los salones Círculo 33 y el del campeón Gabriel Fernández, en la Narvarte y Doctores; se describen los espacios habitacionales en Iztacalco y se comparan con los de la zona norponiente del zócalo capitalino en el Centro Histórico. Se hace un recorrido por Chapultepec, para rematar en la Iglesia de San Hipólito, cerca de la Alameda.

Aquí también las preguntas se entrelazan con aquellas implícitas en todo el libro: ¿A qué tipo de relaciones económicas, políticas y simbólicas responde la lógica espacial? ¿Cómo describir la pertenencia e identificación de un espacio en la construcción de identidades fuertes, sin menoscabo del concepto de exclusión? ¿Es el lugar un espacio multifuncional, multicultural, con una multiplicidad de significados? ¿Cómo atraparlo entonces? ¿Estar en un centro comercial es hacer ciudad? ¿Es un lugar o un no-lugar? ¿Puede cambiar el significado de un lugar comercial a un lugar afectivo?

Y luego: ¿Dónde empieza la ciudad? ¿En las periferias? ¿Que no ahí termina? ¿Cuál es el itinerario de la gente en una ciudad tan grande? ¿Dónde comienza el afuera y el adentro? ¿Es posible entonces hablar de centros y periferias que cambian perceptiva- mente? ¿Cuáles son esos flujos, itinerarios, fronteras, límites, introspecciones y extroversiones de la ciudad?

De este libro destaco tres aspectos fundamentales: 1) La relación entre el lugar practicado, el afuera inmediato $y$ la ciudad; 2) la discusión que surge a partir de la definición e indefinición del lugar y del no-lugar y de lo que ha sido, así lo considero, un error metodológico de muchos académicos al retomar acríticamente el concepto de Marc Augé, y 3 ) la vinculación de los actores urbanos con el lugar.

1. Es fundamental la descripción del lugar, desde la llegada, el estar afuera, la transición y el adentro. Con sus matices, se describe la llegada, desde el microbús al mercado de Sonora, los taxis de los salones de baile, las estaciones del metro en las zonas habitacionales o los autos de Cuicuilco.

Después de la llegada viene la presencia del "acceso", la descripción arquitectónica del lugar, los materiales de construcción, la estructura física del edificio, los acabados en pisos y muros, las cortinas, las puertas, la pequeñez del acceso en el Alicia, la entresala de cortinas en el salón Los Ángeles, las escaleras peligrosas del Aditec, la conversación espacial que se hace entre $L a$ Tortuga y la Lilí, como una vitrina del espacio interior practicado, la esquina de la peluquería, como otro espacio masculino, etcétera. Todos los autores realizaron una detallada descripción del espacio físico que se vinculaba al espacio practicado y percibido. La pequeñez, la amplitud, la extensión, los límites, la atmósfera, los olores, los colores, las texturas, la temperatura 
(el sudor goteando del techo del Alicia, por ejemplo).

Es notoria la intención de articular el lugar con la ciudad. Y aunque acordaríamos que la magnitud de la ciudad de México podría impedirnos abrazarla toda, y eso hace que se fragmente en pedazos, es posible notar con el trabajo empírico de cada capítulo las redes enormes, los flujos intensos, la trama social, cultural y urbana que tejen todos estos lugares. Se nombran delegaciones como zonas urbanas. Se nombran otros lugares de concurrencia, otros referentes espaciales de los asiduos a estos sitios. Se describen desde esquinas y los usos del suelo de los alrededores, las estaciones del metro, hasta los puntos de conexión más allá de lo local, como en el caso de los centros comerciales que tienen una influencia territorial más extensa.

El libro puede ser un referente para el análisis de dos escalas distintas del espacio urbano, el del lugar cotidiano y el de su relación con el conjunto de la ciudad. Precisamente por eso, es importante corresponder la descripción etnográfica con un análisis territorial de los espacios descritos; por ejemplo, en un mapa de la ciudad de México realizar distintos esquemas y bocetos del espacio simbólico, zonificar las apropiaciones sociales, establecer los flujos y los itinerarios, exponer la vida nocturna de la ciudad, la ciudad de las tinieblas, de las complicidades, de los antros, de la sexualidad. Pensemos en este sentido en la diferenciación analítica que hace Armando Silva del concepto de mapa oficial con respecto del croquis simbólico.
El análisis territorial puede hacerse en nivel más amplio a escala urbana, pero también es factible realizarlo del lugar. Aun cuando en los capítulos de la segunda parte se incluyeron tímidamente algunas fotos y algunos mapas, parecen más bien ilustraciones y no herramientas de trabajo etnográfico; se convierten en una alusión al sitio, pero no en un instrumento de análisis semiótico, que permita explicar significados e interpretaciones que autores y actores han hecho del espacio urbano.

El antropólogo y el sociólogo que analizan el espacio y el lugar necesitan recurrir a técnicas visuales, de imágenes, de uso analítico de mapas y planos; tanto así como los arquitectos, geógrafos y urbanistas necesitan emplear las técnicas etnográficas y cualitativas para percibir el espacio más allá de sus fronteras físicas y encontrar la parte simbólica y cultural de su apropiación. Para pensar en la interdisciplina, no únicamente debemos entrelazar a las antropologías, sociologías y psicologías, sino pensar asimismo en una fusión importante con la arquitectura, el urbanismo y la geografía, por no decir la historia y la filosofía.

\section{El segundo aspecto es el concepto} del lugar. Abilio Vergara lo caracteriza por tener un lenguaje particular, una ritualización, una red conceptual, una jerarquización interna, una demarcación, una biografía y una historia.

Existe aquí una similitud con la definición de Marc Augé sobre lugar. Para este autor, un lugar es el que ocupan los nativos que en él viven, trabajan y lo defienden; ahí donde marcan sus fronteras y establecen la huella de sus antepasados. El lugar es el de la experiencia cotidiana, de la significación simbólica, de la memoria y la tradición. Todo eso forma identidades relacionadas con el territorio y con el espacio practicado, como también lo señala De Certau.

Por lo tanto, el no-lugar de Augé es aquel lugar que no tiene o no genera identidad. Es pues la negación del lugar, del no trabajo, el lugar que no defiendes, donde no se marcan fronteras, que no deja huella. Algunos ejemplos serían los viaductos, los trenes supermodernos, los centros comerciales y los aeropuertos.

No obstante esta línea de explicación, la evidencia muestra que en una ciudad ningún lugar es no-lugar. Aun los pasos a desnivel son lugares practicados por alguien y representan entonces lugares para esas personas. Siempre habrá lugares para unos que podrán ser a su vez "no lugares" para otros y viceversa. Las descripciones emprendidas en este libro muestran empíricamente este debate teórico. Podemos estar en contra de la manera como se usa el espacio en un centro comercial de clase media y alta, pero eso no significa que no sea un lugar. Podemos anteponer la cultura popular, que también es profundamente consumista, al consumo de masas mediático, pero eso no significa que una sea constructora de identidad y el otro no. Podemos hablar de construcciones imaginarias distintas, pero no negarlas. El metro, en otro ejemplo, es referente y es tránsito; es tren que se ocupa y es un lugar de paso. En la definición de Augé sería un no-lugar. Pero para los gays, como para muchos otros tam- 
bién, el metro es un lugar fundamental de encuentro y reconocimiento. El metro puede ser un "no-lugar" para algunos, pero es, para otros, un lugar.

3. Finalmente, el tercer aspecto destaca la diversidad de actores y las diferentes perspectivas que resultan de estudiar los lugares desde la etnografía. Distintas visiones populares y de clase se tienen sobre los salones de baile, los centros comerciales, las plazas, los conjuntos habitacionales, los mercados o las iglesias; distintas perspectivas generacionales que se dan principalmente en el antro Alicia y Plaza Universidad; visiones de género en el uso del baile para jóvenes, en los billares, en los lugares gays, en los lugares masculinos como la peluquería o la esquina del barrio.

Todo ello puede parecer una enorme ensalada inconexa de expresiones culturales, muy variadas entre sí. Superlativas diversidades. Pienso en el hecho de que en un salón de baile convergen desde empleados y obreros, amas de casa hasta profesionales con posgrado. Viven en el barrio donde se ubica el salón, o vienen de lejos, desde Neza, Coyoacán o la Gustavo A. Madero. Se combinan así múltiples experiencias culturales tanto como redes sociales y espaciales que entretejen la ciudad.

Pero otros lugares muestran una práctica más nítida de segregación socioespacial. Si bien el uso de las plazas públicas también es indistinto, no es así el de los centros comerciales, que depende más del estatus. Los analizados en este libro son más bien de clase media y alta, pero hay centros

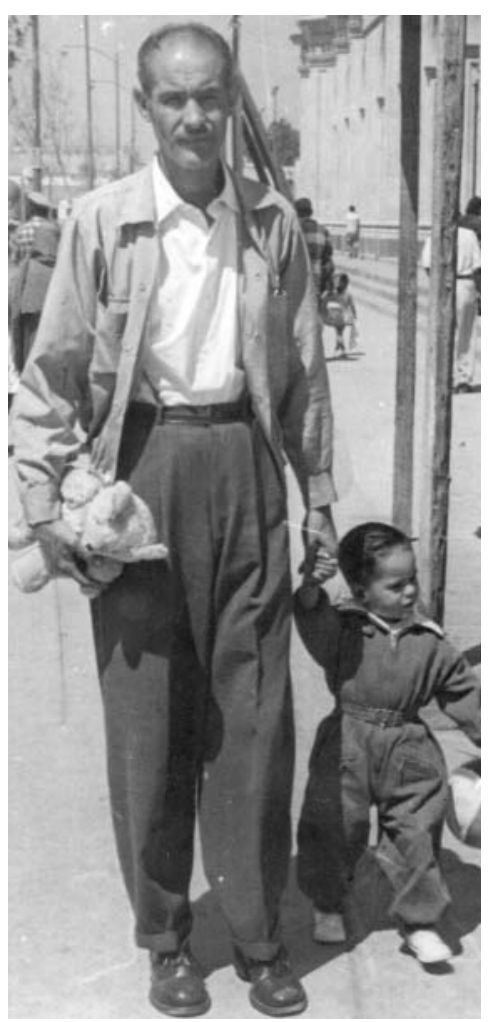

Década de 1950. Calendario Coriac 2000 / Cortesía de Coriac.

comerciales populares, donde otros son los excluidos. Los lugares segregan por una condición de clase, basada más que nada en la diferencia de ingresos y en el estatus. Pero también segregan por una condición de género, cultural, generacional y, me atrevo a decir, a partir de una relación intensa de sexualidades, entre hombres y mujeres, entre hombres y hombres o entre mujeres y mujeres. La Lilí gay excluye, Los Ángeles excluye, el Alicia de grupos juveniles excluye, la peluquería masculinizante excluye. En muchos casos la exclusión es por una actitud de defensa de la identidad, de sobrevivencia. Ante tal relación de sexualidades, podríamos preguntarnos: ¿Qué dicen los hombres de sí mismos, de su masculinidad? ¿Qué dicen de sus órganos sexuales? ¿Cómo se tocan y qué dicen de las mujeres? ¿Qué dicen las mujeres de los hombres, qué piensan, cómo se tocan, cómo expresan corporalmente la sensualidad y la sexualidad? El cortejo y el ligue estarán presentes en los centros comerciales, en el mercado, entre trabajadores y comerciantes. Las infidelidades y las transacciones emocionales también condicionan la experiencia de un lugar.

Los trabajos etnográficos como éstos pueden mostrar las tensiones ineludibles de la experiencia humana si se orientan a aclarar las nuevas formas de la alienación de las clases en el trabajo, en la residencia y en el esparcimiento. La cultura, como la considera la teoría crítica desde Gramsci hasta Habermas, se convierte en una losa pesadísima sobre los hombros de hombres y mujeres sin distinción. Cuando estos puntos identitarios tan diversos entre sí se conecten nuevamente se producirá entonces un discurso hegemónico de poder, desde los distintos ámbitos culturales donde se mueven los hombres y las mujeres, y podrá pensarse así en otras cosas vinculadas a la liberación y a las utopías.

Mientras eso suceda, es de fundamental importancia comprender las formas en que se expresa esta cultura urbana, en toda su diversidad, pero también en sus elementos homogéneos. Por eso pienso que este libro no debe leerse por partes, porque todo el libro es mucho más que la suma de sus artículos. 